\title{
A novel COMP mutation in a pseudoachondroplasia family of Chinese origin
}

\author{
Li Dai ${ }^{{ }^{*}}$, Liang Xie ${ }^{1}$, Yanping Wang ${ }^{1}$, Meng Mao ${ }^{2}$, Nana Li ${ }^{1}$, Jun Zhu ${ }^{3^{*}}$, Christopher Kim ${ }^{4}$ and Yawei Zhang ${ }^{4}$
}

\begin{abstract}
Background: Pseudoachondroplasia (PSACH) is caused exclusively by mutations in the gene for cartilage oligomeric matrix protein (COMP). Only a small number of studies have documented the clinical phenotype and genetic basis in Chinese PSACH patients.

Case presentation: We investigated a four-generation PSACH pedigree of Chinese Han origin. Two patients and two unaffected individuals were recruited for clinical evaluation and molecular genetic analysis. The genomic DNA was extracted from peripheral blood leukocytes. Polymerase chain reaction (PCR) was adopted to amplify the 8-19 exons of COMP gene. Then the products were sequenced bi-directionally for screening mutation. Clinical evaluation revealed that PSACH patients in this pedigree had a severe disproportionate short stature $(-10 S D)$. A heterozygous TGTCCCTGG insertion in exon 13, between nucleotide 1352T and 1353G, were identified in the patients except the unaffected individuals, which resulted in a three-amino-acid insertion (451V_452P ins VPG) in the sixth calmodulin-like repeat of the COMP protein.
\end{abstract}

Conclusion: This C. 1352_1353ins TGTCCCTGG is a novel mutation responsible for severe familial PSACH.

\section{Background}

Pseudoachondroplasia (PSACH, OMIM 177170) is a rare autosomal dominant osteochondrodysplasia characterized by typical disproportionate short stature, brachydactyly, lower limbs anomalies, joint laxity, scoliosis, early onset osteoarthritis, epiphyseal and metaphyseal abnormalities. It is estimated to affect at least 1 in 20,000 persons $[1,2]$. The affected individual has a normal length at birth,and growth retardation generally will not be recognized until two or three years of age. Notably, all patients have normal craniofacial appearance and intelligence [1,3-5].

The PSACH gene was initially localized to chromosome 19 in 1993 [6,7]. Mutations on the Cartilage Oligomeric Matrix Protein (COMP) gene were subsequently found to cause PSACH and another skeletal dysplasia, multiple epiphyseal dysplasia $[8,9]$. COMP protein is a

\footnotetext{
* Correspondence: daili@scu.edu.cn; zhu_jun1@163.com

'National Center for Birth Defects Monitoring, West China Second University Hospital, Sichuan University, 20 Ren Min Nan Lu Section 3, Chengdu 610041, China

${ }^{3}$ National office for Maternal and Child Health Surveillance, West China Second University Hospital, Sichuan University, 20 Ren Min Nan Lu Section 3, Chengdu 610041, China

Full list of author information is available at the end of the article
}

large secreted pentameric glycoprotein of the thrombospondin family, expressed in the extracellular matrix (ECM) surrounding the cells that make up ligaments and tendons. COMP monomer consists of an amino-terminal domain, four type IIepidermal growth like repeats, eight type III calmodulin-like repeats (CLRs), and a carboxylterminal globular domain. Numerous mutations of COMP gene have been found to date, most of them occur in the CLR regions $(\sim 85 \%)$, while others in the Cterminal globular domain $(\sim 15 \%)$ (the Human Gene Mutation Database, http://www.hgmd.cf.ac.uk/ac/index. php). Although the normal function is not fully known, the pathological link between gene mutation, protein alteration, abnormal cell growth and PSACH has been established [1,10-17]. More than 60 COMP mutations have been identified to be with PSACH $[10,18]$, but only a few in Chinese patients $[19,20]$. Severe short stature (-6 SD) in PSACH has been associated with mutations in exon 13, particularly in the region encoding CLR7 of COMP protein [21]. Elliott AM et al recently detected the c. $812 \mathrm{~A} \rightarrow \mathrm{T}$ in exon 8 in a sporadic Inuit PSACH patient with severe short stature (-7.5 SD) [22]. In the present study, we examined the COMP gene for mutations in a Chinese family affected by severe PSACH. 


\section{Case presentation}

\section{Subjects and methods}

This family was initially contacted in the Sichuan province through a member hospital in the Chinese Birth Defects Monitoring Network. PSACH disorder was transmitted through at least four generations in this family. (Figure 1) After informed consent, two affected (III 1 and IV 2) and two healthy persons (III 3 and IV 4) received a comprehensive physical examination and had blood samples taken for mutation screening. The clinical records and radiographic images were published under the patients' written permission. This study was approved by the Research Ethics Committee of Sichuan University.

Using a commercially available kit (Bio Teke, Beijing, China), genomic DNA was isolated from blood samples utilizing the standard protocol provided by the manufacturer of the kit. The procedure used for amplifying COMP exons 8-19 (accession number NM000095) and PCR is outlined previously [23]. The resulting product was purified, separated by PAGE, and sequenced bidirectionally using an $\mathrm{ABI} 3730 x \mathrm{x}$ sequencer.

\section{Clinical features and skeletal radiographic findings}

Pedigree analysis revealed six individuals affected by severe short stature within a span of four generations and the disorder exhibited dominant autosomal transmission. All affected individuals demonstrated the typical characteristics of PSACH: disproportionate shortlimb dwarfing, short upper limbs, lower limb abnormities, waddling gait, but normal facial features and intelligence. The abnormalities of the affected members in this family appeared at about one year of age, usually presenting as difficulties in learning to walk and delayed growth compared with normal children. The proband (III 1, Figure 1) was $99.6 \mathrm{~cm}$ tall at 45 years of age $(-10.6 \mathrm{SD}$ on a normal growth curve of rural Chinese male adults [24]; -1 SD on PSACH curve [25]), less than

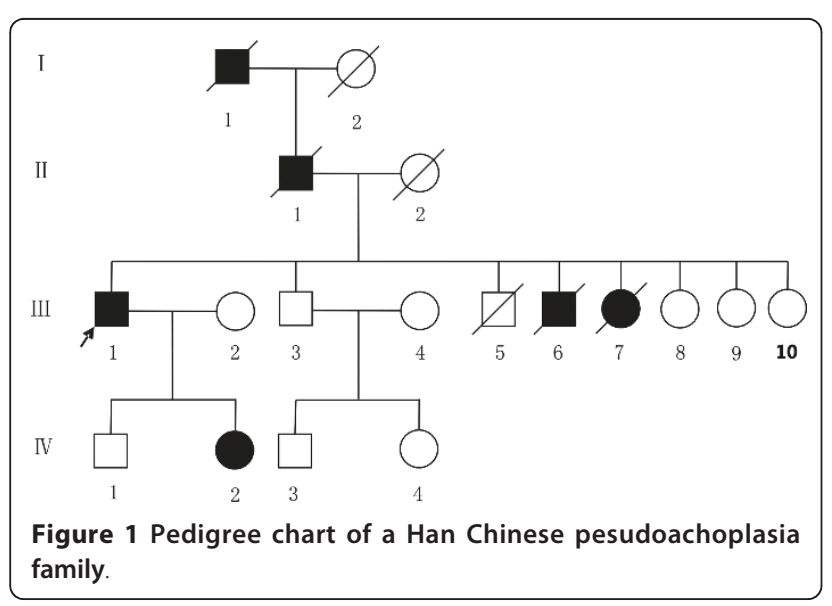

the average height of $101.8 \mathrm{~cm}$ of typical rural-born 4year-old boys [24]. He had strikingly short limbs (upper limb length $41.2 \mathrm{~cm}$ ), small hands, short fingers, crus varum and waddling gait. A lateral spine radiograph (Figure 2) indicated platyspondyly and anterior beaking of the vertebrae. His phalanges and metacarpals were short with cone-shaped epiphyses. (Figure 2) The AP view of pelvis radiograph (Figure 2) showed small femoral heads, irregular acetabulae, enlarged acetabular angles and widened symphysis pubis. His affected daughter (IV2, Figure 1) demonstrated similar characteristics, (Figure 2) albeit somewhat more severe than her father. She was only $96 \mathrm{~cm}$ tall $(-11.2 \mathrm{SD}$ on a normal growth curve of rural Chinese females at 16 years [26]; -1 SD on PSACH curve [24]) when was referred to hospital at 16 years of age, which is comparable to the height of a 3-year-old rural-born girl, far shorter than the $156 \mathrm{~cm}$ average height of 16-year-old rural-born girls [24]. The proband's brother (III6, Figure 1, died two years ago) was afflicted by a shorter stature.

\section{Mutational analysis of the COMP gene}

After sequencing the COMP exons 8-19 in the two patients and two unaffected individuals, a heterozygous 9 bp insertion (c.1352_1353insTGTCCCTGG) was identified between nucleotide $1352 \mathrm{~T}$ and 1353G in exon13, which is located at the end of the sixth repeat of the type-3 calcium-like repeat region of the COMP gene. (Figure 3) As a consequence, three additional amino acids, valine, proline and glycine, were inserted between residues $451 \mathrm{~V}$ and $452 \mathrm{P}$ of the COMP protein (p.451V_452PinsVPG). A recent analysis indicated that the residues $451 \mathrm{~V}$ and $452 \mathrm{P}$ are in a calcium-binding pocket domain of COMP protein [27]. The result was confirmed by repeat sequence analysis.

\section{Conclusion}

Up to now, COMP is the only gene known to be associated with pseudoachondroplasia. COMP mutations and pathological consequences have been extensively studied in Caucasians, but a few in the Chinese population. Besides the c. $815 \mathrm{C} \rightarrow \mathrm{T}$ in exon 8 [19] and the c.1447-1455del [20] in exon 13 of COMP gene reported lately in Chinese PSACH patients, we identified the c. 1352_1353insTGTCCCTGG within exon 13 of COMP that contributes to severe PSACH phenotype in a Han Chinese pedigree. This novel trinucleotide expansion was located in the region coding the sixth CLR (p. $451 \mathrm{~V} \_452$ PinsVPG) and expands the knowledge of COMP mutations leading to PSACH.

PSACH mutations are located in exons 8-14 of COMP gene encoding the type III CLRs of COMP protein $[3,18,28]$. The most frequent mutation, present in one third of PSACH patients, is the deletion of GAC 


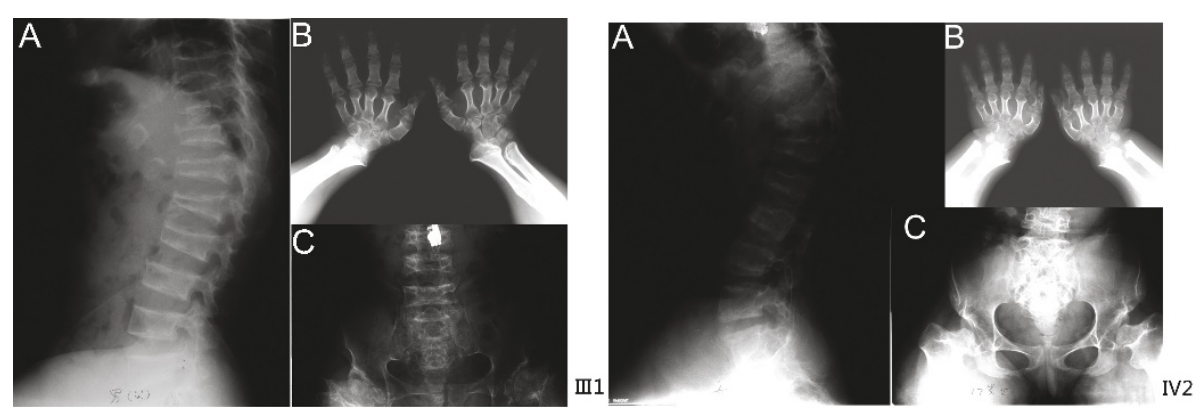

Figure 2 Similar radiographic features for individual III1 and IV2. (A) Anterior beaking of the vertebral bodies and distinctive plantyspondyly, mild lumber lordosis. (B) Short metacarpals and phalanges, small carpal bones, cone-shaped epiphyses, irregular metaphyses of the ulna and radius. (C) Mild scoliosis, small femoral heads, flared metaphyseal borders, poorly developed acetabulae with enlarged acetabular angles, and widened symphysis pubis.

(c.1405-1419delGAC) in a very short triplet repeat (GAC5), which encodes five consecutive aspartic acid residues within the CLR7 of the protein, usually referred as p.469delD, p.473 delD or p.del D469-473 [3,8,29,30]. Most other COMP mutations involve the substitution of one amino acid for another in the COMP protein. Trinucleotide expansion at the region encoding type III CLRs of the protein has now been reported in this study and one other previous study [31]. Genotype-phenotype studies revealed that mutations in CLR7 were associated with more severe PSACH phenotypes than those in elsewhere in the CLRs [21]. The early onset characteristics of PSACH, severe short stature, generalized dysplasia of epiphyses and metaphyses, in these individuals with mutations in other CLRs continues to enforce the importance of the COMP gene.

COMP is a multifunctional structural protein that affects cellular attachment, proliferation and chondrogenesis. It also participates in the ECM assembly through interactions with numerous proteins including types I, II, IV, XI, XII collagen, decorin, fibronectin and matrilin-3 [32,33]. According to the newly published crystal structure of the COMP protein [27], the

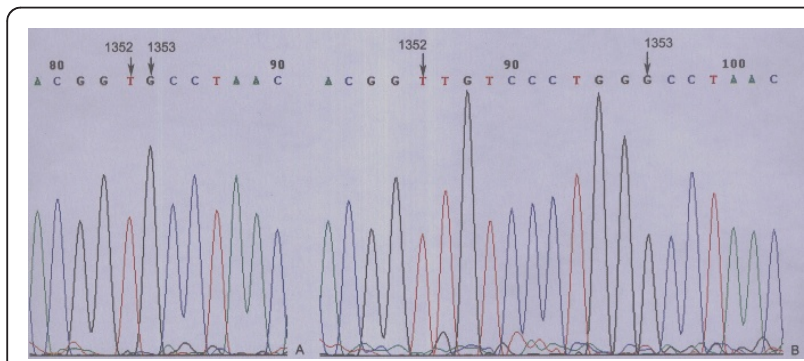

Figure 3 The mutation, c.1352_1353insTGTCCCTGG, in exon 13 of COMP gene. (A) Normal DNA fragment encoding animo acids Thr-Val-Pro-Asn; (B) mutant sequence encoding animo acids Thr-Valval-Pro-Gly-Pro-Asn.
p.451V_452PinsVPG was located to a pocket structure in the end of the sixth CLR of the COMP protein, where a calcium ion is embedded. Calcium supports the binding of COMP to fibronectin which reportedly influences the conformation of COMP [32]. Specifically, alterations in CLRs make calcium-dependant protein folding malfunction [11,30,32,34-37], lead to the assembly of mutant COMP and other proteins in the rER of affected chondrocytes [33]. This intracellular retention is cytotoxic and prevents efficient secretion of these proteins, alters the extracellular matrix and results in premature chondrocyte death. Eventually, the upregulated apoptosis of chondrocytes from the growth plate diminishes linear growth, and the abnormal ECM causes early onset osteoarthritis observed in PSACH patients $[1,38-40]$. In PSACH, only a small fraction of COMP pentamers (3\% or less) contains all wild-type COMP subunits, most of the COMP pentamers contain one or more mutant subunits that exert dominant negative effects $[8,30]$. A mouse model built by Posey et al. recapitulated this cellular pathology of human PSACH, including the retention of ECM proteins, intracellular matrix formation in the rER cisternae, and increased apoptosis of chondrocyte [11]. Previous studies have shown that calcium-binding is critical in the function of the COMP protein, and missense mutations or in-frame deletions in the calmodulin-like repeats region reduces this ability [1]. The longer amino acids sequence in CLR6 due to this novel mutation may have similar negative effects on the function of the COMP protein, the proliferation and apoptosis of chondrocytes. This study suggests that the $9 \mathrm{bp}$ insertion can be responsible for the severe phenotype in the Chinese family in despite no direct functional evidence. In conclusion, the c.1352_1352insTGTCCCTGG within exon 13 of COMP expands the spectrum of mutations that causes PSACH. It could be of value to the molecular diagnosis, 


\section{genotype-phenotype relationship understanding and pathogenesis of this disorder.}

\author{
Abbreviations \\ PSACH: pseudoachondroplasia; COMP: cartilage oligomeric matrix protein; \\ CLR: calmodulin-like repeat domain; ER: endoplasmic reticulum; ECM: \\ extracellular matrix.
}

\section{Acknowledgements}

We are very grateful to the persons who participated in this work. This work was supported in part by the National Natural Science Foundation of China (Grant ID: 30700679, mutation screening), by the State Key Basic Research Project (Grant ID: 2007CB511905, specimen collection), and by the National Institutes of Health Fogarty training grants 1D43TW008323-01 and 1D43TW007864-01.

\section{Author details}

${ }^{1}$ National Center for Birth Defects Monitoring, West China Second University Hospital, Sichuan University, 20 Ren Min Nan Lu Section 3, Chengdu 610041, China. ${ }^{2}$ Department of Pediatrics, West China Second University Hospital, Sichuan University, 20 Ren Min Nan Lu Section 3, Chengdu 610041, China. ${ }^{3}$ National office for Maternal and Child Health Surveillance, West China Second University Hospital, Sichuan University, 20 Ren Min Nan Lu Section 3, Chengdu 610041, China. ${ }^{4}$ Yale University School of Public Health, 60 College street, New Haven, CT 06520, USA.

\section{Authors' contributions}

LD studied the family, designed research plan and prepared manuscript. LX and NL performed the molecular genetic studies, participated in sequence alignment. YW and MM participated in clinical evaluation. JZ participated in collecting specimens and supervised study. CK and YZ reviewed and revised the manuscript. All authors had read the final manuscript and approved the publication of the clinical images.

\section{Competing interests}

The authors declare that they have no competing interests.

Received: 13 December 2010 Accepted: 21 May 2011

Published: 21 May 2011

\section{References}

1. Posey $\mathrm{KL}$, Hecht JT: The role of cartilage oligomeric matrix protein (COMP) in skeletal disease. Curr Drug Targets 2008, 9(10):869-877.

2. Tufan AC, Satiroglu-Tufan NL, Jackson GC, Semerci CN, Solak S, Yagci B: Serum or plasma cartilage oligomeric matrix protein concentration as a diagnostic marker in pseudoachondroplasia: differential diagnosis of a family. Eur J Hum Genet 2007, 15(10):1023-1028.

3. Briggs MD, Chapman KL: Pseudoachondroplasia and multiple epiphyseal dysplasia: mutation review, molecular interactions, and genotype to phenotype correlations. Hum Mutat 2002, 19(5):465-478.

4. McKeand J, Rotta J, Hecht JT: Natural history study of pseudoachondroplasia. Am J Med Genet 1996, 63(2):406-410.

5. Wynne-Davies R, Hall CM, Young ID: Pseudoachondroplasia: clinical diagnosis at different ages and comparison of autosomal dominant and recessive types. A review of 32 patients (26 kindreds). J Med Genet 1986, 23(5):425-434.

6. Briggs MD, Rasmussen IM, Weber $J$, Yuen J, Reinker K, Garber AP, Rimoin DL, Cohn DH: Genetic linkage of mild pseudoachondroplasia (PSACH) to markers in the pericentromeric region of chromosome 19. Genomics 1993, 18(3):656-660.

7. Hecht JT, Francomano CA, Briggs MD, Deere M, Conner B, Horton WA, Warman M, Cohn DH, Blanton SH: Linkage of typical pseudoachondroplasia to chromosome 19. Genomics 1993, 18(3):661-666.

8. Hecht JT, Nelson LD, Crowder E, Wang Y, Elder FF, Harrison WR, Francomano CA, Prange CK, Lennon GG, Deere M, et al: Mutations in exon $17 \mathrm{~B}$ of cartilage oligomeric matrix protein (COMP) cause pseudoachondroplasia. Nat Genet 1995, 10(3):325-329.

9. Briggs MD, Hoffman SM, King LM, Olsen AS, Mohrenweiser H, Leroy JG, Mortier GR, Rimoin DL, Lachman RS, Gaines ES, et al:
Pseudoachondroplasia and multiple epiphyseal dysplasia due to mutations in the cartilage oligomeric matrix protein gene. Nat Genet 1995, 10(3):330-336.

10. Wang CH, Lin WD, Tsai A, Tsai FJ: Novel human pathological mutations. Gene symbol: COMP. Disease: pseudoachondroplasia. Hum Genet 2009, 125(3):350.

11. Posey KL, Veerisetty AC, Liu P, Wang HR, Poindexter BJ, Bick R, Alcorn JL, Hecht JT: An inducible cartilage oligomeric matrix protein mouse model recapitulates human pseudoachondroplasia phenotype. Am J Pathol 2009, 175(4):1555-1563.

12. Chen $T L$, Posey $K L$, Hecht JT, Vertel BM: COMP mutations: domaindependent relationship between abnormal chondrocyte trafficking and clinical PSACH and MED phenotypes. J Cell Biochem 2008, 103(3):778-787.

13. Pirog-Garcia KA, Meadows RS, Knowles L, Heinegard D, Thornton DJ, Kadler KE, Boot-Handford RP, Briggs MD: Reduced cell proliferation and increased apoptosis are significant pathological mechanisms in a murine model of mild pseudoachondroplasia resulting from a mutation in the C-terminal domain of COMP. Hum Mol Genet 2007, 16(17):2072-2088.

14. Hecht JT, Hayes E, Haynes R, Cole WG: COMP mutations, chondrocyte function and cartilage matrix. Matrix Biol 2005, 23(8):525-533.

15. Posey KL, Hayes E, Haynes R, Hecht JT: Role of TSP-5/COMP in pseudoachondroplasia. Int J Biochem Cell Biol 2004, 36(6):1005-1012.

16. Hecht JT, Montufar-Solis D, Decker G, Lawler J, Daniels K, Duke PJ: Retention of cartilage oligomeric matrix protein (COMP) and cell death in redifferentiated pseudoachondroplasia chondrocytes. Matrix Biol 1998, 17(8-9):625-633.

17. Hecht JT, Deere M, Putnam E, Cole W, Vertel B, Chen H, Lawler J: Characterization of cartilage oligomeric matrix protein (COMP) in human normal and pseudoachondroplasia musculoskeletal tissues. Matrix Biol 1998, 17(4):269-278.

18. Stenson PD, Mort M, Ball EV, Howells K, Phillips AD, Thomas NS, Cooper DN: The Human Gene Mutation Database: 2008 update. Genome Med 2009, 1(1):13.

19. Xude Zhang, Yan Meng, Yuanyuan Peng, Huiping Shi, shimin Zhao, Shangzhi Huang: Gene mutation analysis in a pseudoachondroplasia (PSACH) family. Zhongguo Shi Yong Erke Za Zhi 2010, 25(4):289-291.

20. Liu FX, Li ZL, Wei ZJ, Meng Y, Ren CA, Zhang XD, Yu MX, Huang SZ: Genetic analysis and serum level of cartilage oligomeric matrix protein in patients with pseudoachondroplasia. Chin Med J (Engl) 2010, 123(16):2181-2184.

21. Mabuchi A, Manabe N, Haga N, Kitoh H, Ikeda T, Kawaji H, Tamai K, Hamada J, Nakamura S, Brunetti-Pierri N, et al: Novel types of COMP mutations and genotype-phenotype association in pseudoachondroplasia and multiple epiphyseal dysplasia. Hum Genet 2003, 112(1):84-90.

22. Elliott $A M$, Bocangel $P$, Reed $M H$, Greenberg CR: A novel COMP mutation in an Inuit patient with pseudoachondroplasia and severe short stature. Genet Mol Res 2010, 9(3):1785-1790.

23. Kennedy J, Jackson G, Ramsden S, Taylor J, Newman W, Wright MJ, Donnai D, Elles R, Briggs MD: COMP mutation screening as an aid for the clinical diagnosis and counselling of patients with a suspected diagnosis of pseudoachondroplasia or multiple epiphyseal dysplasia. Eur J Hum Genet 2005, 13(5):547-555.

24. Yang XG, Li YP, Ma GS, Hu XQ, Wang JZ, Cui ZH, Wang ZH, Yu WT, Yang ZX, Zhai FY: Study on weight and height of the Chinese people and the differences between 1992 and 2002. Zhonghua Liu Xing Bing Xue Za Zhi 2005, 26(7):489-493.

25. Horton WA, Hall JG, Scott Cl, Pyeritz RE, Rimoin DL: Growth curves for height for diastrophic dysplasia, spondyloepiphyseal dysplasia congenita, and pseudoachondroplasia. Am J Dis Child 1982, 136(4):316-319.

26. Cheng RQ, Shen $S X$, Tu YZ, Xia H, Wang H, Zhi DJ, Yao JJ, Sun L, Hong QR, Ye JF, et al: A cluster systemic sampling survey of the body height distribution profile and the prevalence dhort stature of urban and suburban children aged from 6 to 18 years in Shanghai. Zhongguo Xun Zheng Er Ke Za Zhi 2009, 4(1):5-11.

27. Tan $K$, Duquette $M$, Joachimiak $A$, Lawler J: The crystal structure of the signature domain of cartilage oligomeric matrix protein: implications for collagen, glycosaminoglycan and integrin binding. FASEB J 2009, 23(8):2490-2501.

28. Newton G, Weremowicz S, Morton CC, Copeland NG, Gilbert DJ, Jenkins NA, Lawler J: Characterization of human and mouse cartilage oligomeric matrix protein. Genomics 1994, 24(3):435-439. 
29. Briggs MD, Mortier GR, Cole WG, King LM, Golik SS, Bonaventure J, Nuytinck L, De Paepe A, Leroy JG, Biesecker L, et al: Diverse mutations in the gene for cartilage oligomeric matrix protein in the pseudoachondroplasia-multiple epiphyseal dysplasia disease spectrum. Am J Hum Genet 1998, 62(2):311-319.

30. Hou J, Putkey JA, Hecht JT: Delta 469 mutation in the type 3 repeat calcium binding domain of cartilage oligomeric matrix protein (COMP) disrupts calcium binding. Cell Calcium 2000, 27(6):309-314.

31. Delot E, King LM, Briggs MD, Wilcox WR, Cohn DH: Trinucleotide expansion mutations in the cartilage oligomeric matrix protein (COMP) gene. Hum Mol Genet 1999, 8(1):123-128.

32. Thur J, Rosenberg K, Nitsche DP, Pihlajamaa T, Ala-Kokko L, Heinegard D, Paulsson M, Maurer P: Mutations in cartilage oligomeric matrix protein causing pseudoachondroplasia and multiple epiphyseal dysplasia affect binding of calcium and collagen I, II, and IX. J Biol Chem 2001, 276(9):6083-6092.

33. Hecht JT, Hayes E, Snuggs M, Decker G, Montufar-Solis D, Doege K, Mwalle F, Poole R, Stevens J, Duke PJ: Calreticulin, PDI, Grp94 and BiP chaperone proteins are associated with retained COMP in pseudoachondroplasia chondrocytes. Matrix Biol 2001, 20(4):251-262

34. Kvansakul M, Adams JC, Hohenester E: Structure of a thrombospondin Cterminal fragment reveals a novel calcium core in the type 3 repeats. EMBO J 2004, 23(6):1223-1233.

35. Kleerekoper Q, Hecht JT, Putkey JA: Disease-causing mutations in cartilage oligomeric matrix protein cause an unstructured $\mathrm{Ca} 2+$ binding domain. J Biol Chem 2002, 277(12):10581-10589.

36. Maddox BK, Mokashi A, Keene DR, Bachinger HP: A cartilage oligomeric matrix protein mutation associated with pseudoachondroplasia changes the structural and functional properties of the type 3 domain. J Biol Chem 2000, 275(15):11412-11417.

37. Chen $H$, Deere $M$, Hecht JT, Lawler J: Cartilage oligomeric matrix protein is a calcium-binding protein, and a mutation in its type 3 repeats causes conformational changes. J Biol Chem 2000, 275(34):26538-26544.

38. Dinser R, Zaucke F, Kreppel F, Hultenby K, Kochanek S, Paulsson M, Maurer P: Pseudoachondroplasia is caused through both intra- and extracellular pathogenic pathways. J Clin Invest 2002, 110(4):505-513.

39. Posey KL, Yang Y, Veerisetty AC, Sharan SK, Hecht JT: Model systems for studying skeletal dysplasias caused by TSP-5/COMP mutations. Cell Mol Life Sci 2008, 65(5):687-699.

40. Hashimoto $Y$, Tomiyama T, Yamano Y, Mori H: Mutation (D472Y) in the type 3 repeat domain of cartilage oligomeric matrix protein affects its early vesicle trafficking in endoplasmic reticulum and induces apoptosis. Am J Pathol 2003, 163(1):101-110

Pre-publication history

The pre-publication history for this paper can be accessed here: http://www.biomedcentral.com/1471-2350/12/72/prepub

doi:10.1186/1471-2350-12-72

Cite this article as: Dai et al: A novel COMP mutation in a

pseudoachondroplasia family of Chinese origin. BMC Medical Genetics 2011 12:72.

\section{Submit your next manuscript to BioMed Central and take full advantage of:}

- Convenient online submission

- Thorough peer review

- No space constraints or color figure charges

- Immediate publication on acceptance

- Inclusion in PubMed, CAS, Scopus and Google Scholar

- Research which is freely available for redistribution

Submit your manuscript at www.biomedcentral.com/submit
Biomed Central 